\title{
2-DOF PIEZOELECTRIC ACTUATOR CONTROLLER BASED ON FPGA
}

\begin{abstract}
SUMMARY
This article presents the method for controlling the piezolegs motor with the application of the FPGA(Field-programmable gate array) system and presents the results of conducted tests of the motor slider displacement, with various steering signal configurations. It includes also the review of piezoelectric motors solutions and characteristics of systems, based on FPGA systems. Suggested steering solution can be used for subsequent tests on piezolegs drives and can constitute positioning system element.
\end{abstract}

Keywords: FPGA controller, piezoelectric, piezolegs

\section{STEROWANIE SILNIKIEM LINIOWYM PIEZOELEKTRYCZNYM ZA POMOCA UKEADU FPGA}

Artykut przedstawia metodę sterowania silnikiem liniowym piezoelektrycznym typu piezolegs za pomoca układu FPGA oraz wyniki przeprowadzonych pomiarów przemieszczenia końca biegnika silnika, przy różnych konfiguracjach sygnatów sterujących. Dokonano również przeglądu rozwiazań silników piezoelektrycznych oraz określono cechy systemów opartych na układach FPGA. Sugerowane rozwiazanie sterowania może być wykorzystane do dalszych badań nad napędami typu piezolegs i może stanowić element systemu pozycjonowania.

Slowa kluczowe: FPGA, sterownik, piezolegs, piezoelektryczny

\section{INTRODUCTION}

The elements, made of piezoelectric materials, are capable of making repeatable, small displacements, what makes them attractive for micro-movement positioning applications, like microrobots, microscopes and ultra precise machine tools (Merry et al. 2007). Increasing requirements for precise systems, concerning precision and speed of positioning, render the tests on the piezoelectric drives extremely important. Piezoelectric motors attain high speeds, allowing, in the same time, for very precise positioning of the movable part. The specificity of this kind of drives is based on not using the magnetic field and the fact that together with the miniaturization the efficiency of the drives does not fall.

Information concerning the control method contributes to increasing the possibility of their application in micro-systems, whereas the test results provide basic parameters, used for designing such system types.

The notion of control system is to be understood as the programmable part, as well as the hardware architecture of the system, allowing for the realization of the control algorithm. The capabilities and the efficiency of the system are directly related to the characteristics of the above mentioned structures. The hardware characteristics must include: structure complexity, speed and reliability of operation, power consumption etc. The system programme characteristics depend on optimization of the programme code, type of programming language, software tools. The optimal solution is using the systems, which enable the intervention of the designer into the architecture configuration, both on the programme level as well and on the hardware level.
One of the basic requirements of the modern design assumes the possibility of testing and modifying the system on each stage of the project. One can say, that the synergy level of the control system with the remaining elements of the mechatronic system and its flexibility are the priority factors, which should be used in the decision-making process, when choosing the right equipment for the project. Reprogrammable systems, owing to the easy integration and decreased costs, enable construction of the systems on one chip.

The availability and choice of FPGA systems, which are diversified in architecture structure and in price, enables their application in various control systems. They can be used in controlling the robotized systems, with various kinematics configurations (Sałek 2003). Looking at the process of designing the systems, the knowledge regarding the capability and range of application of programmable systems is very important. Both issues are directly bound with structure, complexity of functional resources and functional characteristics of programmable systems. FPGA systems are well suited for long-lasting industrial products, in machines, which require fast market introduction, in unique or individual hardware solutions or which require easy modification without any construction changes.

It is particularly important, when constructing the testing equipment, especially when preparing digital installations and systems. This last application requires so called development boards. FPGA systems are used in many modern fields of engineering such as: industrial automation, robotics, telecommunication, medicine and military engineering (Versteyhe et al. 1999).

The above characteristics of FPGA systems and the requirements concerning piezoelectric drive control, enabled

* AGH University of Science and Technology, Faculty of Mechanical Engineering and Robotics, Department of Robotics and Mechatronics, al. A. Mickiewicza 30,30-059 Kraków, Poland; daniel.prusak@agh.edu.pl; gkarpiel@agh.edu.pl; kgac@agh.edu.pl 
construction of control system, which, especially at the level of tests, should ensure quick reconfiguration and quick change of control signal parameters.

In the literature, the piezoelectric motors are divided into two groups, depending on the principle of operation (Merry et al. 2007). The first of them are so called inchworm motors. The classic construction is characterized by application of three independent piezoelectric converters (Merry et al. 2007, Salisbury et al. 2007, Shamoto and Moriwaki 1997, Valiviita and Vainio 1999, Zhang and Zhu 1997). The principle of operation of this engine enforces special conditions for mounting each of the motor converters. This kind of solution involves problems with constant and smooth movement. It is the result of need to maintain continuity of transformations in the relations between the individual piezoelectric converters.

The second group of piezoelectric motors constitutes of elliptical motors (Merry 2007, Aoyagi et al. 2002, Egashira et al. 2001, Ueha and Tomikawa 1994). The ability of elliptical movements of the converter's end is used in such types of constructions. These motors can be controlled by the signals with frequency of $20 \mathrm{kHz}$ or higher and are called ultrasonic motors. They can reach the speed of up to $100 \mathrm{~mm} / \mathrm{s}$.

Tests on ultrasonic motors have shown, that there is the stick-slip effect between the surface of the converter and slider at low speed, and therefore they should not be used in positioning systems, where low speed is required (Versteyhe et al. 1999). Alternatively the elliptic piezoelectric motors can be controlled with sub-ultrasonic frequency signals. These motors display much smaller tendencies to the stick-slip phenomenon. Finally, in order to avoid the stickslip effect, a decision was made to use elliptic motors called piezolegs. The motors with such a structure were designed by Piezomotors Uppsala AB (Piezomotor AB 2004).

Piezoleg motors use four controlled piezoelectric legs, performing elliptic stepping movement, as the result of which the discontinuing friction clutch changes the positions of the motor slider. The principle of operation of a dimorphic converter was used during the process of construction of the legs, i. e. the leg consists of two electrically isolated piezoelectric stacks, which are induced by independent control signals (Merry et al. 2007). Such solution types enable the constant control of speed of particular piezoelectric motors. The piezoelectric leg movement area is limited, according to the constructive assumptions to the area of a rhomb. The smooth operation of the drive, the control signals should be chosen in such way, that the leg movement trajectory would have a continuous derivative in the $(x, y)$ plane (Johansson et al. 2004).

The first part of the article shows the construction of the piezoelectric motor, used for tests and the control system implemented in the FPGA system. The following part of the article describes the control system, which enables displacement testing and registered control signals and includes also the results of conducted tests. The last chapter of the article contains the remarks and conclusions learnt, based on the analysis of the collected measurement results.

\section{PIEZOLEG MOTOR}

The tests were conducted on the piezoleg type piezoelectric motor manufactured by PiezoMotor Uppsala AB, model LL1011A (Piezomotor AB 2004). The motor consisted of four piezoelectric legs, which were controlled with electric signals. Each of the legs in the upper part consists of so called pad, which is used as coupling between the leg surface and the motor slider. The pad is made of material, which provides sufficient friction (i.e. aluminium oxide) The remaining surface of the leg is most frequently casted in rubber, to ensure the proper damping during operation. The size of the motor is presented in figure 1 , it weighs $23 \mathrm{~g}$.
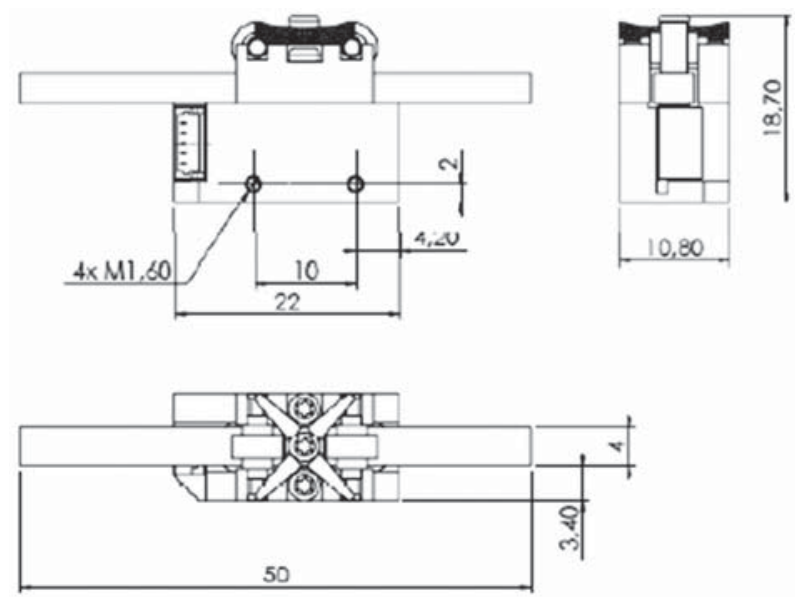

Fig. 1. Construction and dimensions of PiezoMotor Uppsala $\mathrm{AB}$, model LL1011A

The motor leg is made of two piezoelectric stacks, separated with an isolator (dielectric). Providing the electrical impulse results in opposite piezoelectric phenomenon, which results in elongation of the stack.

\section{CONTROL SYSTEM}

\subsection{Algorithm}

Figure 2 shows the intersection model of the piezoelectric motor, which illustrates the motor leg principle of operation. Elongation along the $y$ axis takes place in case of providing at the same time electrical voltage to both piezoelectric stacks, the legs is made of. Providing various voltage signals to both of the stacks results in deviation of the motor's leg from the $y$ axis. Changing the values of voltages supplied to the stacks of one leg enables controlling the position of leg end in the operation area on the $(x, y)$ plane, in the range of the signal amplitude $u_{i}(t)(V), i=\{1,2,3,4\}$ for $\min \left(u_{i}\right)=0 \mathrm{~V}$ and $\max \left(u_{i}\right)=10,20,30,46 \mathrm{~V}$.

It can be observed in figure 2 , that the motor legs always operate together in pairs. The first pair of legs $p_{1}$, consists of legs $A$ and $C$, and is controlled with signals $U_{1}$ and $U_{2}$. The second pair of legs $p_{2}$, consists of legs $B$ and $C$, and is controlled with 
signals $U_{3}$ and $U_{4}$. Drive control is based on providing correspondingly signals $u_{i}(t)(V), i=\{1,2,3,4\}$ enabling the instant elongation of one pair of legs (in the direction of $y$ axis), and as a result they are in contact with the slider surface.

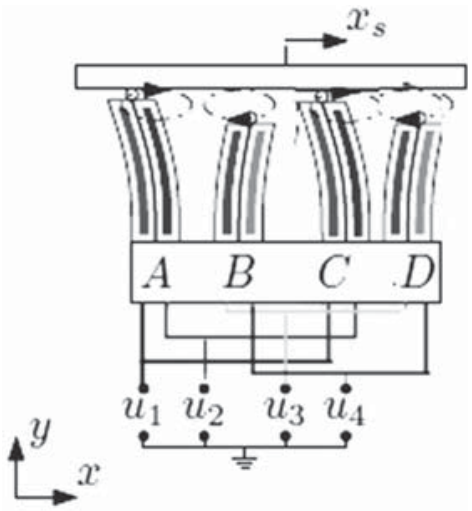

Fig. 2. Piezolegs drive model and the sequence of leg

The location of the end of the legs with respect to the direction of $x$ axis and $y$ axis can be presented with the following equations (Merry et al. 2007):

$$
\begin{aligned}
& x_{p 1}(t)=c_{x}\left(u_{1}(t)-u_{2}(t)\right) \\
& x_{p 2}(t)=c_{x}\left(u_{3}(t)-u_{4}(t)\right) \\
& y_{p 1}(t)=c_{y}\left(u_{1}(t)+u_{2}(t)\right) \\
& y_{p 2}(t)=c_{y}\left(u_{3}(t)+u_{4}(t)\right)
\end{aligned}
$$

where $c_{x}(m / V)$ and $c_{y}(m / V)$ are constant coefficients, correspondingly of bending and stretching (Shamoto and Moriwaki 1997).

The range of piezoelectric motor leg movement has the shape of a rhomb, presented in figure 3 . Its vertices are numbered in order to present the end positions of the operation end of the legs (the pad). The direction of subsequent positions determines the movement direction of motor slider.

\subsection{The implementation of the control algorithm}

The control algorithm used the hardware platform from Altera (DE0-nano board), presented in figure 4, equipped with
FPGA system from the product family of Cyclone IV (model EP4CE22F17C6N). This system contains in its structure 22320 logic elements (Altera 2012).

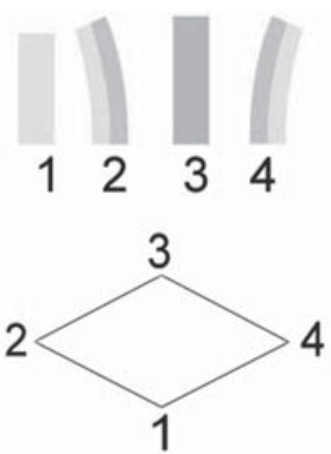

Fig. 3. Range of motion of a piezoelectric motor leg and leg strain in the extreme points

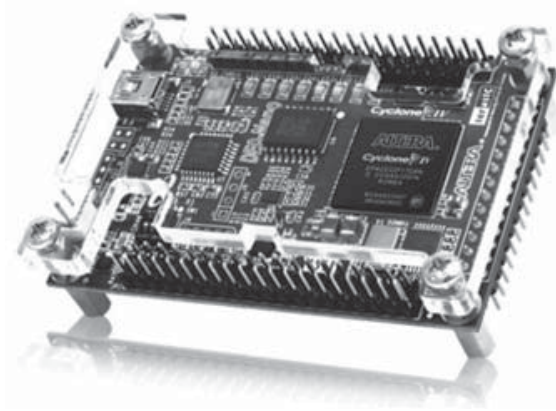

Fig. 4. Altera DE0-nano bard based on Cyclone IV family

A specially designed module was used to control the motor piezoelectric drive, its logic structure was recorded in VerilogSystem language (Fig. 5). This module enables controlling the drive in full speed or step mode, which enables adjustment of the slider relocation speed. Additionally, it is possible to insert the limited value of steps. The module start-up configuration enables adjustment of acceleration cycle. As the result, the performed simulation of the control signals and module adjustment configuration were presented on respective cyclograms in figures 6 and 7.

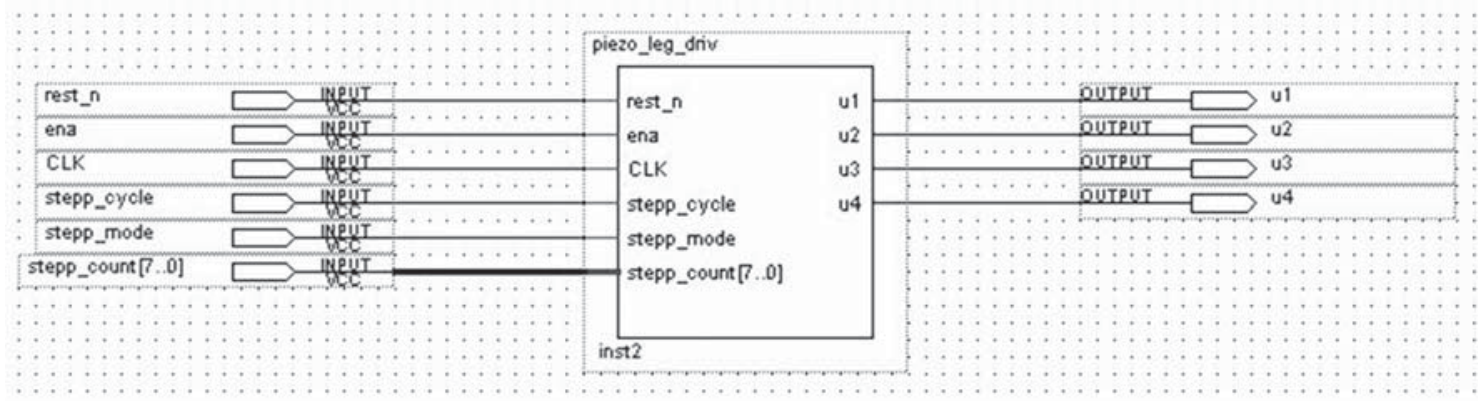

Fig. 5. The control unit for the piezolegs drive 


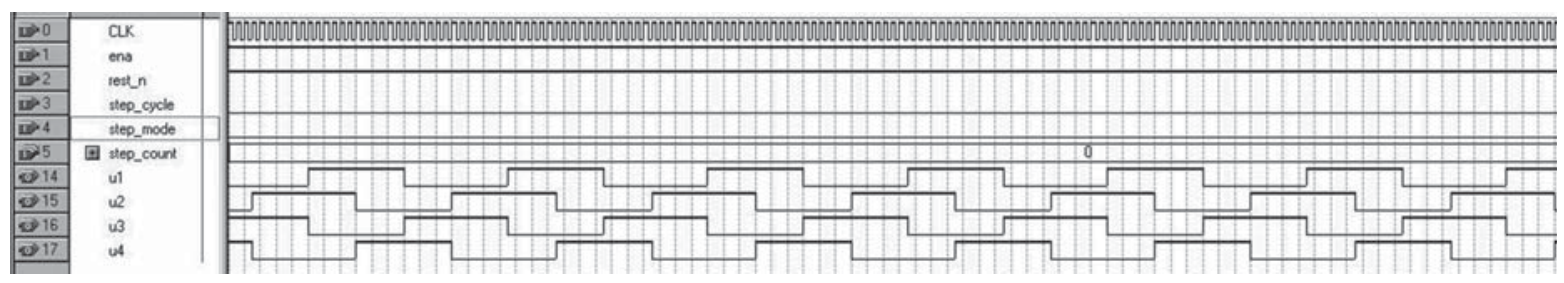

Fig. 6. Digital control signals for the full speed

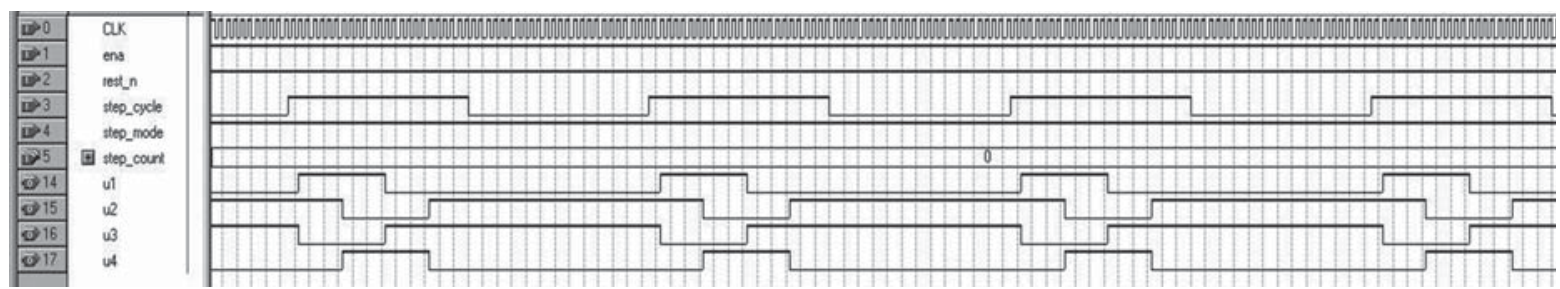

Fig. 7. Digital control signals for the step mode

\subsection{Measurement system}

The position measurement of piezoelectric piezoleg type motor slider was conducted using the SP2000TR laser interferometer made by SIOS (SIOS 2012). The measuring range of the device is $2000 \mathrm{~mm}, 1 \mathrm{~nm}$ resolution. Figure 8 shows the block diagram and laboratory stand of the measuring system, used for research on piezoelectric motor slider.

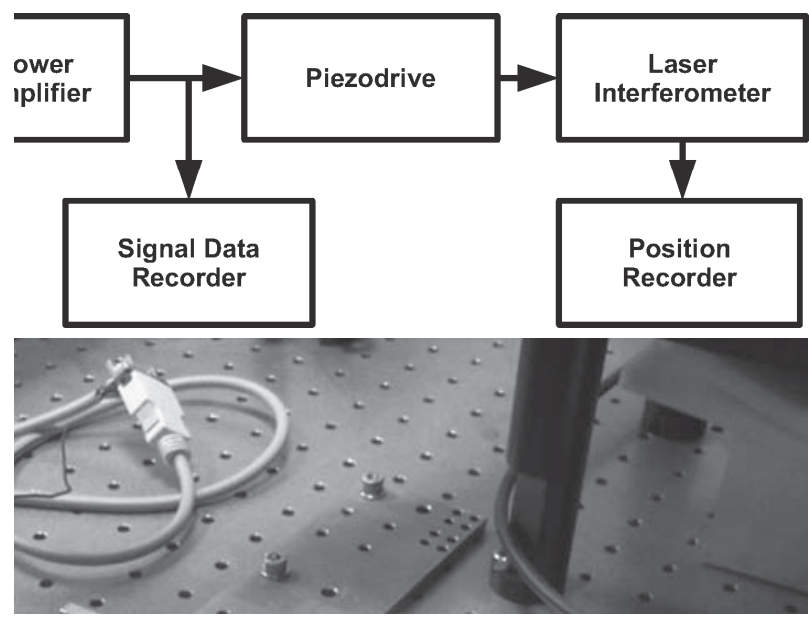

Fig. 8. Measuring system: a) block diagram, b) laboratory stand

\section{2-DOF PIEZODRIVE}

Figure 9 shows the linear model with two degrees of freedom. On the left side the CAD model of the drive is shown. On the right is the real construction. The stator can be extended and rotated.

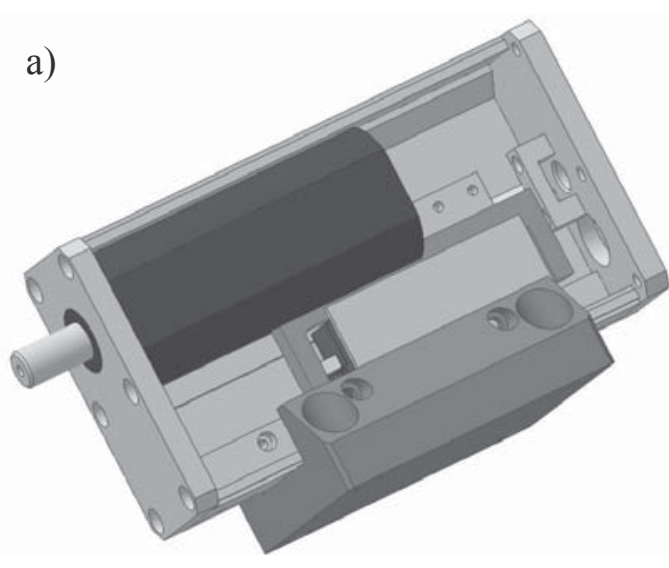

b)



Fig. 9. 2-DOF piezodrive: a) CAD model, b) real construction

\section{EXPERIMENTAL RESULTS}

In order to verify the operation correctness the control signals were registered during operation in all modes: full speed (Fig. 10), step by step (Fig. 11), and smooth motor start-up (Fig. 12). Next, measurements of location and 
D. PrusaK, G. Karpiel, K. GaC

speed of motor operating in step by step mode, with various sample maximum voltage values for stacks of piezoelectric legs: $46 \mathrm{~V}$ (Fig.13), $30 \mathrm{~V}$ (Fig. 14), $20 \mathrm{~V}$ (Fig. 15) and 10 V (Fig. 16).

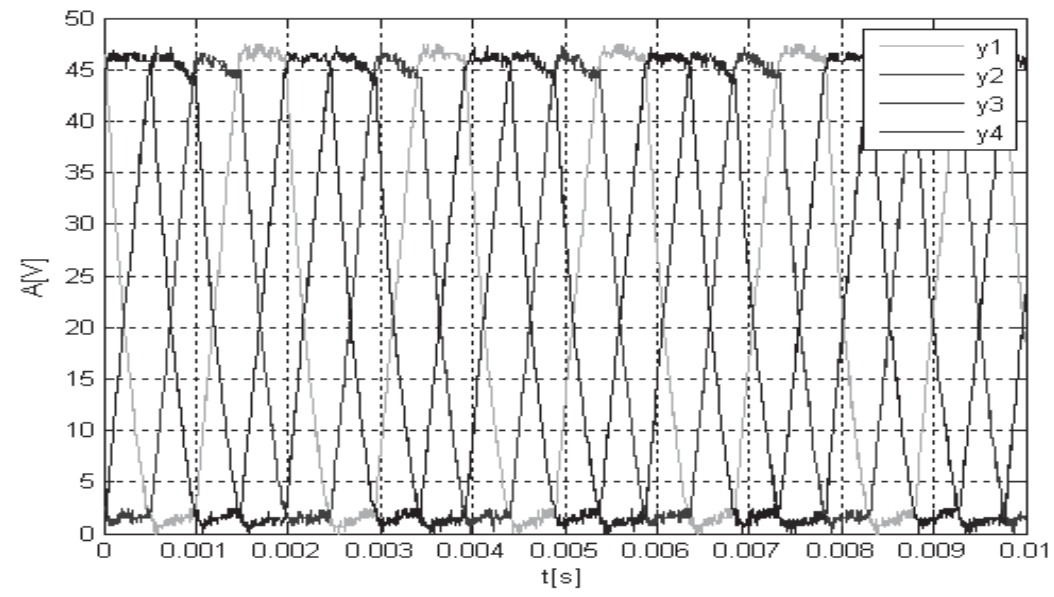

Fig. 10. Analog control signals for the full speed

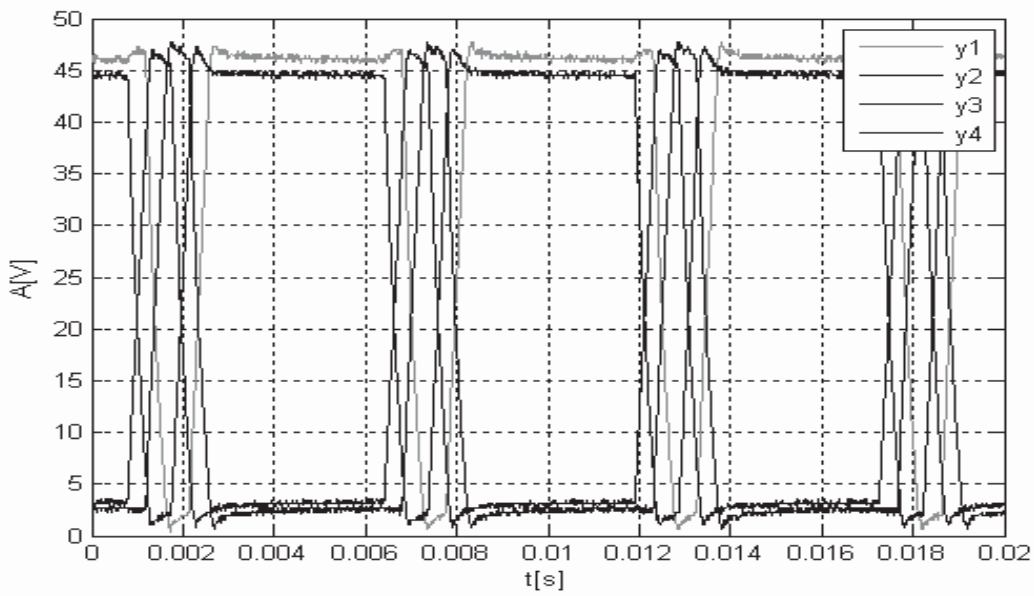

Fig. 11. Analog control signals for the step mode

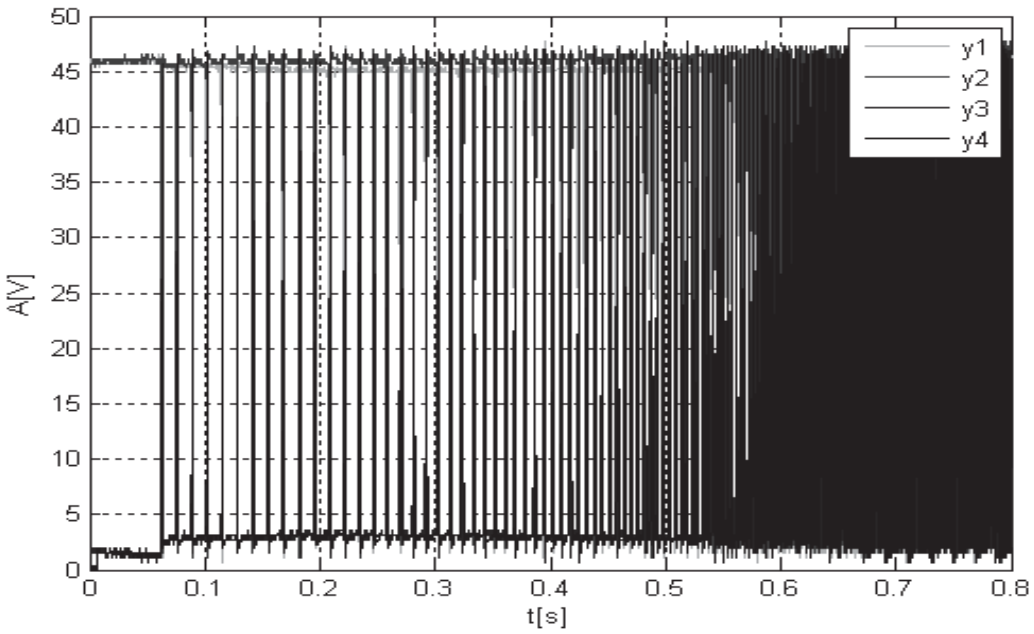

Fig. 12. Smoth motor start-up 

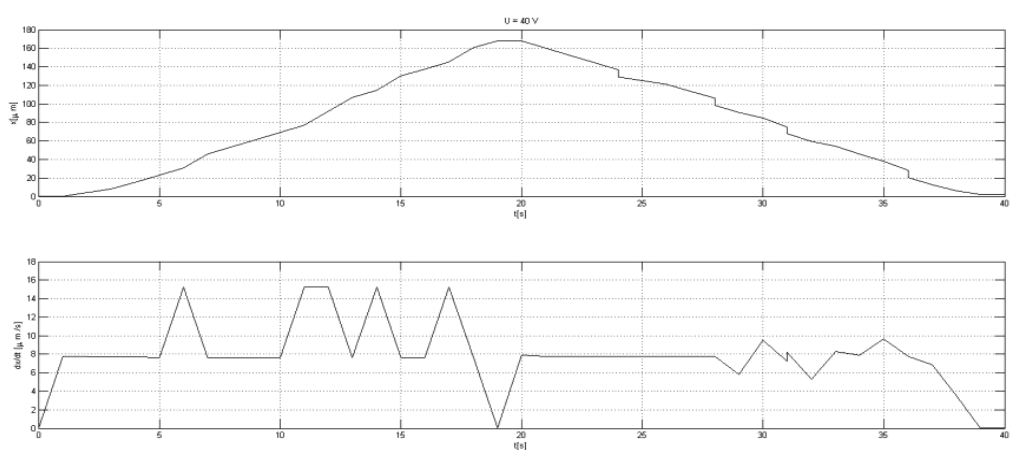

Fig. 13. Position and speed of the slider of piezolegs for $46 \mathrm{~V}$ amplitude


Fig. 14. Position and speed of the slider of piezolegs for $30 \mathrm{~V}$ amplitude
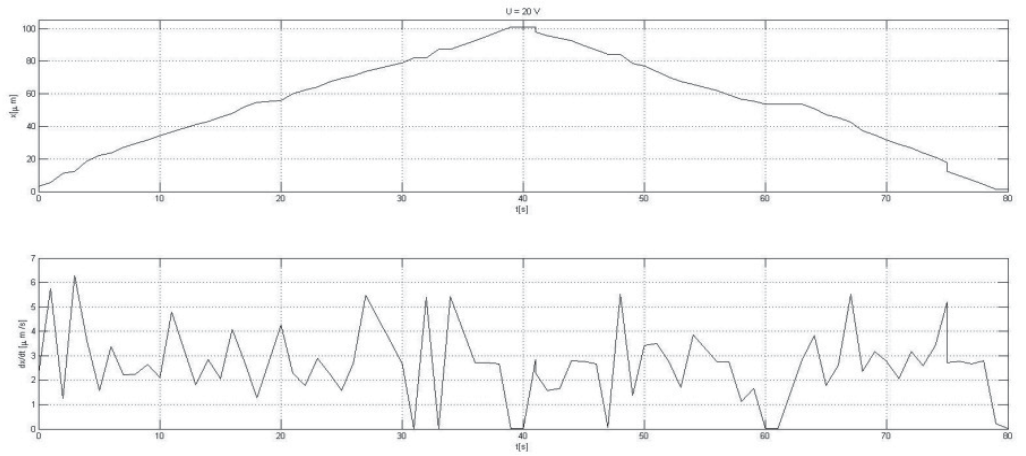

Fig. 15. Position and speed of the slider of piezolegs for $20 \mathrm{~V}$ amplitude
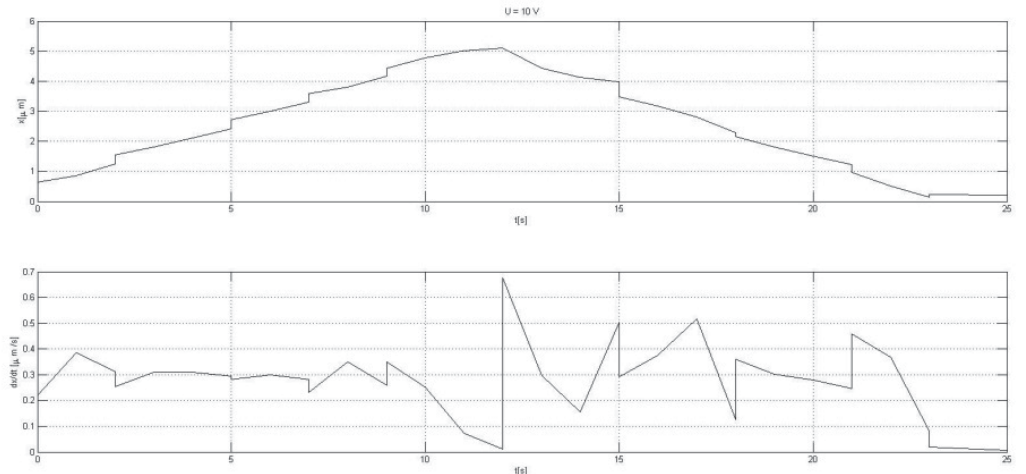

Fig. 16. Position and speed of the slider of piezolegs for $10 \mathrm{~V}$ amplitude 


\section{RESULTS AND CONCLUSION}

The measurements of the piezoelectric motor slider were conducted using the laser interferometer and provided data enabling describing the application range of the motor controlling method using the rectangular signals. The courses of control signals were presented in fig. 10 allow for adjusting motor in the full speed mode. In order to measure the speed of the piezoelectric motor slider the step by step control method was used, the courses of control signals are shown in the diagram figure 11. The above controlling method enabled conducting the motor acceleration test, shown in figure 12.

Additionally, slider position tests were conducted, in case of limiting control signal amplitude. The subsequent measuring results for amplitude $46 \mathrm{~V}, 30 \mathrm{~V}, 20 \mathrm{~V}$ and $10 \mathrm{~V}$ were shown in the form of diagrams in figures 13, 14, 15, 16. These characteristics allow for using the selected control method used for designed executive systems. As it is seen in case of step by step steering method, there is a large characteristics nonlinearity of tested slider speed. It reduces the ability to apply the method for signals, which do not theoretically require large amount of positioning movement fluidity. Reduction of the maximum value of the control signals amplitude does not influence on operation of piezoelectric motor in regard of speed and relocation, whereas it influences the maximum strength of the motor slider.

To provide the full applicability of the proposed controlling method, it is necessary to conduct strength tests, depending on the amplitude of controlling signals. The applied solution of drive control for piezolegs type drives can constitute an element of control system in a closed loop i.e. control with coupling from position measurement.

\section{References}

Altera 2012, http://www.altera.com/devices/fpga/cyclone-iv/cyiv-index.jsp Aoyagi M, Beeby S.P. WhiteN.M. 2002, A novel multi-degree-of-freedom thick-film ultrasonic motor. IEEE Transactions on Ultrasonics 5, Ferro-electrics and Frequency Control, 49(2), pp. 151-158.

EgashiraY., Kosaka K., Takada S., Iwabuchi T., Baba T. Moriyama S., Harada T., Nagamoto K., Nakada A., Kubota H., Ohmi T. 2001, 0.69 nm resolution ultrasonic motor for large stroke precision stage. IEEE Conference on Nanotechnology, pp. 397-402.

Johansson S., Bexell M., Jansson A. 2004, Fine control of electromechanical motors. Patent $6,798,117$

Merry R., de Kleijn N., van de Molengraft R., Steinbuch M. 2007, 16th IEEE International Conference on Control Applications, Part of IEEE Multi-conference on Systems and Control Control of a high precision stage using a walking piezo actuator, 1-3 October.

Piezomotor AB. PiezoLEGS motor 2004, www.piezomotor.com.

Salisbury S.P., Waechter D.F., Mrad R.B., Prasad S.E., Blacow R.G., Bin Y. 2007, Closed-loop control of a complementary clamp piezoworm actuator. IEEE/ASME Transactions on Mechatronics, 12(6), pp. 590$-598$.

Sałek L.A., 2003, Zaawansowane technologie w nowoczesnych ukladach sterowania. Cito Systems, Inc.3940 Freedom Circle, Santa Clara, CA 95054, USA.

Shamoto E, Moriwaki T.. Development of a "walking drive" ultraprecision positioner. Precision Engineering,1997, 20(2), pp. 85-92.

SIOS 2012, http://www.sios.de.

Ueha S., Tomikawa Y. 1994, Ultrasonic Motors: Theory and Applications. Monographs in: Electrical and Electronic Engineering. Clarendon Press, Oxford, ISBN 0-19-859376-7.

Valiviita S., Vainio O. 1999, Delayless dierentiation algorithm and its ecient implementation for motion control applications. IEEE Transactions on Instrumentation and Measurement, 48(5), pp. 967-971.

Versteyhe M., Reynaerts D., Van Brussel H.1999, Hybrid force-position control of clamping with a piezo-stepper. IEEE Control Systems Magazine, 19(2), pp. 31-39.

Wójter D., Jasiński K. 2008, Układy FPGA. Możliwości powszechnego zastosowania. Przegląd Telekomunikacyjny, nr 2-3.

Zhang B., Zhu Z., 1997, Developing a linear piezomotor with nanometer resolution and high stiness. IEEE/ASME Transactions on Mechatronics, 2(1), pp. 22-29. 